\title{
Outcomes and safety of concomitant topiramate or metformin for antipsychotics-induced obesity: a randomized-controlled trial
}

\author{
Congjie Wang ${ }^{1 *}$, Wenjie Shi ${ }^{1}$, Jianyang $\mathrm{Xu}^{2^{*}}$, Chengbing Huang ${ }^{1}$ and Jiannan Zhu ${ }^{1}$
}

\begin{abstract}
Background: Although there are some existing data describing the usage of topiramate in patients with antipsychotic-induced obesity, study on its comparison with metformin is limited. This study aimed to explore the effectiveness and safety of concomitant topiramate on antipsychotic-induced obesity as well as its comparison with metformin.
\end{abstract}

Methods: 62 stabilized outpatients with antipsychotic-induced obesity were randomized into the topiramate group and the metformin group with 16-week treatment. The patients' weight, body mass index (BMI), waist-hip ratio, and their side effects were assessed and compared. Intention-to-treat and completer analyses were performed. Meanwhile, covariance analysis was conducted to control the impact of the significant difference in BMI between the two groups.

Results: The two groups had comparable characteristics, though their difference in baseline BMI was significant. (1) Intention-to-treat analyses: the random missing values were replaced using the last observation carried forward method when intention-to-treat analyses were conducted. Compared with the baseline, the weight, BMI, and waisthip ratio in the topiramate group markedly decreased at each follow-up, whereas, in the metformin group, only waist-hip ratio significantly decreased at 4 weeks after treatment. Compared with the metformin, only weight and $\mathrm{BMI}$ in the topiramate group were significantly decreased at week 4 after treatment, and at week 8-16, weight, BMI and waist-hip ratio were remarkably declined. (2) Completer analyses: compared with the baseline, the weight, BMI, and waist-hip ratio in the topiramate group at week 4-16 were markedly decreased, whereas only waist-hip ratio with metformin was significantly decreased at week 4. Compared with the metformin, all BMI with topiramate were markedly decreased at week 4-16. Moreover, its weight and waist-hip ratio also were notably lowered at week 8. No significant differences in adverse events were found between the two groups.

Conclusions: Topiramate, similar to metformin in reducing obesity as previously reported, also significantly reduced body weight, BMI, and waist-hip ratio in patients with antipsychotic-induced obesity and demonstrated well tolerance in psychiatric patients.

Trial registration The trial was registered at http://www.chictr.org.cn, and the number was ChiCTR-IPR-17013122.

\footnotetext{
*Correspondence: jakew19877@163.com; zgjshaxjy@126.com

1 Department of Psychiatry, Huai'an No. 3 People's Hospital, No.272 West

Huaihai Rd., Huai'an 223001, Jiangsu, China

${ }^{2}$ Department of Neurology, Huai'an No. 3 People's Hospital, No.272 West

Huaihai Rd., Huai'an 223001, Jiangsu, China
}

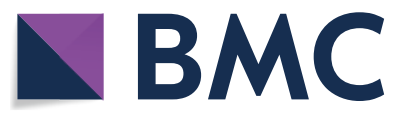

(c) The Author(s) 2020. This article is licensed under a Creative Commons Attribution 4.0 International License, which permits use, sharing, adaptation, distribution and reproduction in any medium or format, as long as you give appropriate credit to the original author(s) and the source, provide a link to the Creative Commons licence, and indicate if changes were made. The images or other third party material in this article are included in the article's Creative Commons licence, unless indicated otherwise in a credit line to the material. If material is not included in the article's Creative Commons licence and your intended use is not permitted by statutory regulation or exceeds the permitted use, you will need to obtain permission directly from the copyright holder. To view a copy of this licence, visit http://creativeco mmons.org/licenses/by/4.0/. The Creative Commons Public Domain Dedication waiver (http://creativecommons.org/publicdomain/ zero/1.0/) applies to the data made available in this article, unless otherwise stated in a credit line to the data. 
Keywords: Topiramate, Metformin, Antipsychotics, Obesity

\section{Introduction}

Previous studies have linked some patient exposure to some second-generation antipsychotics (SGAs) to an increased risk for weight gain or obesity, hyperlipidemia, and impaired glucose metabolism, which properly was related to increased appetite/caloric intake and various receptors, hormones, and peptides have been implicated [1]. In particular, weight gain or obesity induced by SGAs may significantly increase both the risk of cardiovascular disease and mortality from cardiovascular disease [2, 3]. Moreover, the treatment of obesity caused by SGAs still remains a challenge. So far, there is no consensus on the exact effective and safe drug of weight loss, although many measures had been implemented to promote weight loss $[4,5]$.

Apart from behavioral interventions and switching to first generation antipsychotics or other SGAs, many medicines have been utilized to reduce weight gain or obesity induced by SGAs or non-pharmacological obesity in the past. For example, sibutramine, reboxetine, bupropion, orlistat, liraglutide, metformin, topiramate, and antagonism of the histamine $2(\mathrm{H} 2)$ receptor, etc. were also reported to have significant effects on weight gain compared to placebo [6-9], whereas, some previous studies' results were not consistent with each other, even there are some conflicting reports [10].

Metformin, a biguanide drug approved for treatment of type 2 diabetes, has been extensively studied for use of weight gain in the absence of diabetes in typically developing children $[11,12]$. In adults or pediatric patients or adolescents, metformin may prevent or reverse or significantly attenuate weight gain associated with atypical antipsychotics [13-15], although some confound factors are difficult to be excluded, and its effects on body weight mostly were due to reduction in appetite rather than increases in calorie expenditure. Topiramate, a new antiepileptic drug, which is increasingly being used as a mood stabilizer in bipolar disorder, has also been used as adjuvant therapy for both the positive and negative symptoms of schizophrenia [16-18]. And it holds some promise as an adjunctive therapy for both overweight and treatment of psychotic symptoms [6]. Topiramate has the strongest mean weight loss compared with placebo, metformin, $\mathrm{H} 2$ receptor antagonists, and norepinephrine reuptake inhibitors in some reviews $[6,9,19-21]$. The effects of topiramate on patients with obesity caused by SGAs were clearly related to decreasing appetite and increasing satiety, but does not alter energy expenditure, perhaps through inhibition of carbonic anhydrase $[6,22]$, although the differences of topiramate on SGA-associated obesity varied in safety, efficacy, and response to therapy in the different subpopulations of patients with obesity [20-23].

In fact, the treatment of weight gain or obesity induced by antipsychotics still remains a significant challenge to psychiatrists, because there is relatively little evidence of specificity for pharmacological therapies to antipsychotic-induced obesity. Moreover, there is no consensus on the exact effective and safe drug of weight loss until now. Although some studies have evaluated the effects of topiramate or metformin on weight gain, most of them made the comparison with the placebo, and only one investigation with sibutramine [24].

Up to now, there is no research report on the direct comparison of topiramate with metformin on weight gain or obesity induced by SGAs in the real world. Therefore, we hypothesize that topiramate and metformin have the same effects on antipsychotic-related obesity, the aim of this study was to explore the effects of concomitant topiramate or metformin on obesity caused by some SGAs while keeping the patient's illness stable and maintaining the original dosage of antipsychotic medications.

\section{Methods}

\section{Study design and participants}

This study was a 16-week, open design, randomized clinical trial, and all outpatients or inpatients with schizophrenia or affective disorder were Chinese Han population and from Huai'an No. 3 People's Hospital in a naturalistic clinical setting from September, 2012 to December, 2016. The protocol for the study was granted approval from the scientific and ethics committee of Huai'an No. 3 People's Hospital (Ethical Review No. HASYkjk 2012-003). All patients continued to receive the original antipsychotic medications and community psychiatric care or did some light manual works after enrollment, and meanwhile, informed consent was obtained from patients or their legal guardians. Baseline information including vital signs, height, weight, waist and hip circumference, demographic characteristics, psychiatric history, medication history, and medication-related adverse effects was collected. All patients were called for follow-up every 4 weeks for at least 16 weeks after concomitant topiramate or metformin treatment. Patient's weight, height, and waist and hip circumference (W-H ratio) were measured while dressed in light clothing without shoes on the same scale zeroed at each measurement and calculated by investigators at each follow-up 
visit. And blood routine, liver function, and electrocardiogram examination were also conducted as possible as we could at each follow-up visit.

All assessments were done by investigators, and the patients' indicators must be accurately measured although investigators had known the patients' therapy allocation at each follow-up visit. The measurement of height, weight, and waist and hip circumference was conducted by three psychiatric doctors trained with well consistency among them (correlation coefficient $=0.87-0.90$ ).

Patients included in this study were diagnosed with schizophrenia or affective disorder based on Diagnostic and Statistical Manual of Mental Disorders: DSM-IV by reviewing clinic medical records. All outpatients or inpatients' illness $(n=2)$ were in a stable condition, and the age varies from 15 to 55 . Patients had been on antipsychotics for at least 6 months and gained more than 10\% of their body weight on an antipsychotic before enrollment, and currently met the diagnostic criteria for obesity, which was specified as a BMI over $25 \mathrm{~kg} / \mathrm{m}^{2}$ based on the Regional Office for the Western Pacific Region of WHO criteria [25].

Patients were excluded from the study if they had a history of intolerance or hypersensitivity to topiramate and metformin, or had a severe or unstable general medical illness, such as renal and liver function failure, or severe cardiovascular diseases. Patients who were pregnant and/ or during lactation period were also not included.

70 cases of patients with schizophrenia or affective disorder with obesity induced by SGAs met with the inclusion criteria; 8 of them declined to participate the trial after the enrollment. Only 62 cases of obese outpatients $(n=60)$ and inpatients $(n=2)$ with schizophrenia or affective disorder in a stable condition of illness were included in this trail. Patients were randomly assigned to one of two groups using randomized table generated by online smart random $\mathrm{A}$ and $\mathrm{B}$ generator software (A represents the topiramate group; $B$ represents the metformin group). Finally, 32 of 62 cases were assigned to the topiramate group, and 30 cases to the metformin group after enrollment. The outpatients in each group often were lost to follow-up or could not be followed up in time due to some reasons, such as the bad weather condition or personal reasons. The status of the enrollment, and the completed and withdrawn samples between the two groups are shown (see Fig. 1).

\section{Interventions}

After patients were enrolled, all patients and caregivers only received brief counseling and information regarding the patients' dietary management and physical exercise. The dosage of each antipsychotic the patients previously used remained unchanged as much as possible during the trial unless psychotic symptoms exacerbated or severe adverse events emerged. The treatment would be discontinued if investigators decided that a patient's response was not adequate or the patient asked to be withdrawn from the trial due to severe adverse events or illness exacerbation.

It was assumed that the trial medication of topiramate and metformin could induce unpredictable side effects (e.g., augmented sedation, dizziness, or hypoglycemia), which might cause patients to drop-out and make the results difficult/impossible to interpret. For that reason, a gradual increment in dosing of topiramate and metformin was chosen in this trial. Drug doses were chosen to minimize side effects, but retain clinically relevant therapeutic levels according to prior dose-response studies. Therefore, the initial dosage of topiramate was $50 \mathrm{mg}$ twice daily, if tolerated, the maximum dose was 100-200 mg twice daily after 1 week, and the mean daily dose of topiramate was $190.63 \pm 57.41 \mathrm{mg}$ after 16 -week treatment. The initial treatment dosage of metformin was $0.25 \mathrm{~g}$ twice daily, if tolerated, the maximum daily dose of metformin was $1.5 \mathrm{~g}$ after 1 week, and the mean daily dose of metformin was $0.67 \pm 0.22 \mathrm{~g}$ after 16 -week treatment. All patients received diet, drinking, or exercise counseling, and no other requirements were conducted.

\section{Outcome measurements}

The primary outcome was measurement of weight, height, body mass index (BMI), and $\mathrm{W}-\mathrm{H}$ ratio at each follow-up visit, which were measured every 4 weeks for 16 weeks. The BMI was calculated as weight in kilograms divided by height in meters squared, and $\mathrm{W}-\mathrm{H}$ ratio was calculated as waist circumference divided by hip circumference.

The secondary outcomes were measurements of the patient's liver function, blood routine, electrocardiogram at each follow-up visit, and adverse events were also monitored after concomitant topiramate or metformin every 4 weeks. Of course, the psychotic symptoms were also paid close attention to observe at each follow-up visit during the trial.

\section{Statistical analysis}

The statistical analysis was carried out using SPSS 13.0 (SPSS Inc., Chicago, Illinois, USA). The categorical variables were tested using a Chi-square test, and the continuous variables were tested by means of a repeated measurement variance analysis before and after treatment in each group of concomitant topiramate or metformin, and independent samples $t$ test between the two groups. 


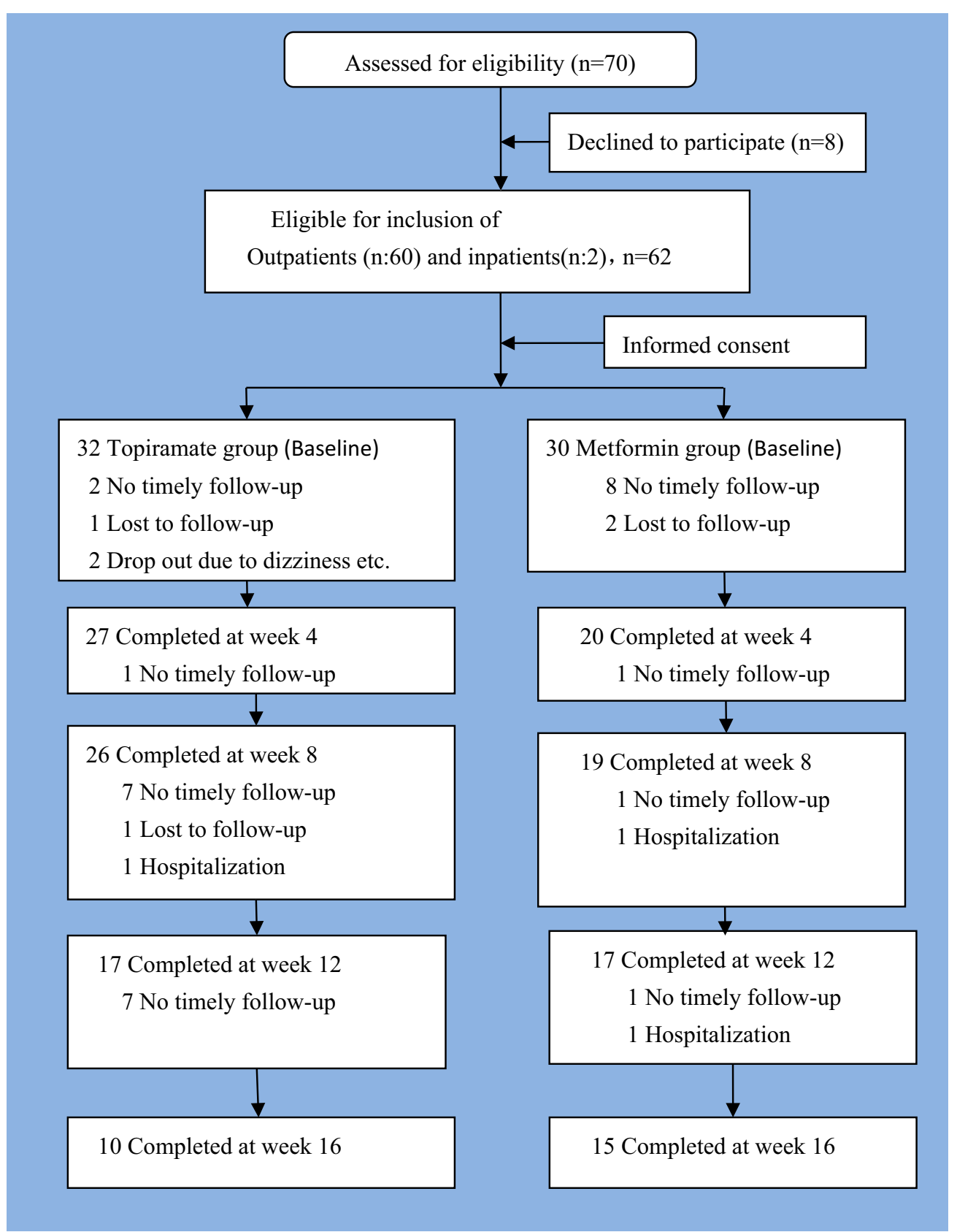

Fig. 1 The diagram showing study design and flow of subjects in the study

All missing data of two groups at each follow-up visit were random missing data by randomized analyses, and the missing data at week 4-16 of follow-up visit were replaced using simple imputation (last observation carried forward method, LOCF) when intention-to-treat (ITT) analyses was performed [26].

An intention-to-treat and completer analyses were performed between the two groups because of higher loss rate of follow-up. Covariance analysis was conducted to control the impact of the significant difference in baseline body mass index (BMI) when compared the patients' weight, BMI, and waist-hip ratio at 4-16 weeks of follow-up visit between the two groups.

All statistical tests were two-tailed. The values represented as mean \pm standard deviation (SD) at each 
follow-up visit. $P$ value $<0.05$ was considered statistically significant.

\section{Results}

62 cases of patients with obesity entered two groups after 16 weeks of the trial. Of 62 cases of patients, there were 32 cases of outpatients or inpatients into the topiramate group and 30 cases into the metformin group respectively (see Fig. 1). It was listed in Table 1 related to patients' demographic, clinical features at baseline, follow-up situation, and types of APS being used after the patients enrolled between the two groups.

\section{Comparison of patients' demographic and clinical features at baseline between the two groups}

There were no statistically significant differences in gender, age, marital status, occupation, educational level, parents' history of obesity, the diagnosis types of mental disorder, chlorpromazine (CPZ) equivalent daily dose of antipsychotics [27, 28], type of antipsychotics, and daily dosage of clozapine and olanzapine being used between the two groups. In addition, no remarkable differences were found in the type and the number of use of combined antipsychotics, affective stabilizers, antidepressants, chlorpromazine (CPZ) equivalent daily dosage of use of combined antipsychotics, and the number of outpatients and inpatients between the two groups. Therefore, the patients' demographic, clinical characteristics, and the factors that continued to influence weight gain during the trial were comparable and matched between the two groups (see Tables 1, 2).

\section{ITT analyses}

The effects of concomitant topiramate or metformin on weight gain, $\mathrm{BMI}$, and $\mathrm{W}-\mathrm{H}$ ratio at each follow-up

Table 1 Comparison of patients' demographic and clinical features at baseline and after the end of the trial between the two groups

\begin{tabular}{|c|c|c|c|c|}
\hline Variables & Topiramate $(n)$ & Metformin (n) & $x^{2} / t$ & $P$ value \\
\hline$n$ & 32 & 30 & & \\
\hline Gender $\left(M_{1} / F\right)$ & $28 / 4$ & $24 / 6$ & 0.64 & $>0.05$ \\
\hline Age (years) & $32.81 \pm 9.11$ & $31.87 \pm 8.48$ & 0.42 & $>0.05$ \\
\hline Marital status $\left(M_{2} / S_{1} / D\right)$ & $9 / 22 / 1$ & $11 / 16 / 3$ & 2.09 & $>0.05$ \\
\hline Occupation (F/J/E) & $15 / 13 / 4$ & $16 / 8 / 6$ & 1.56 & $>0.05$ \\
\hline \multicolumn{5}{|l|}{ Level of education } \\
\hline Primary education & 15 & 13 & 0.44 & $>0.05$ \\
\hline Secondary education & 15 & 16 & & \\
\hline College and above & 2 & 1 & & \\
\hline \multicolumn{5}{|l|}{ Parental obesity } \\
\hline No/yes & $29 / 3$ & $28 / 2$ & 0.15 & $>0.05$ \\
\hline Diagnosis $\left(S_{2} / A D\right)$ & $31 / 1$ & $27 / 3$ & 1.21 & $>0.05$ \\
\hline Inpatients/outpatients & $2 / 30$ & $0 / 30$ & 1.94 & $>0.05$ \\
\hline \multicolumn{5}{|l|}{ The number of patients with/without loss of follow-up } \\
\hline With/without loss of follow-up at week 4 & $5 / 27$ & $10 / 20$ & 2.65 & $>0.05$ \\
\hline With/without loss of follow-up at week 8 & $6 / 26$ & $11 / 19$ & 2.50 & $>0.05$ \\
\hline With/without loss of follow-up at week 12 & $15 / 17$ & $13 / 17$ & 0.08 & $>0.05$ \\
\hline With/without loss of follow-up at week 16 & $22 / 10$ & $15 / 15$ & 2.26 & $>0.05$ \\
\hline CPZ equivalent daily dose of all APS used during the trial & $433.75 \pm 215.57$ & $370.17 \pm 177.07$ & 1.26 & $>0.05$ \\
\hline \multicolumn{5}{|l|}{ The main types of APS currently in use during the trial } \\
\hline Clozapine & 16 & 10 & 3.15 & $>0.05$ \\
\hline Olanzapine & 6 & 6 & & \\
\hline Quetiapine & 2 & 5 & & \\
\hline Risperidone & 4 & 6 & & \\
\hline Other APS, and etc. & 4 & 3 & & \\
\hline Daily dosage of clozapine during the trial $(n: 16,10)$ & $229.69 \pm 121.18$ & $165 \pm 114.99$ & 1.35 & $>0.05$ \\
\hline Daily dosage of olanzapine during the trial $(n: 6,6)$ & $10.0 \pm 6.32$ & $12.08 \pm 5.10$ & 0.63 & $>0.05$ \\
\hline
\end{tabular}

$M_{1}$ male, $M_{2}$ married, $S_{1}$ single, $D$ divorced, $F$ farmer, $J$ jobless, $E$ employee, $S_{2}$ schizophrenia, $A D$ affective disorder, $C P Z$ chlorpromazine, $A P S$ antipsychotics 
Table 2 Concomitant APS, affective stabilizers, and antidepressants between the two groups during the trial

\begin{tabular}{|c|c|c|c|c|}
\hline Variables & Topiramate $(n)$ & Metformin (n) & $x^{2} / t$ & $P$ value \\
\hline $\begin{array}{l}\text { The number of combined use of APS, affective stabilizers and } \\
\text { antidepressants }\end{array}$ & 18 & 27 & & \\
\hline \multicolumn{5}{|l|}{ Types of combined use of APS, and etc. } \\
\hline Clozapine & 2 & 0 & 11.01 & $>0.05$ \\
\hline Olanzapine & 0 & 3 & & \\
\hline Quetiapine & 2 & 1 & & \\
\hline Risperidone & 4 & 5 & & \\
\hline Ziprasidone & 2 & 1 & & \\
\hline Aripiprazole & 2 & 4 & & \\
\hline Perphenazine & 4 & 9 & & \\
\hline Chlorpromazine & 1 & 0 & & \\
\hline Sulpiride & 0 & 1 & & \\
\hline Lithium carbonate & 0 & 1 & & \\
\hline Sodium valproate & 0 & 1 & & \\
\hline Antidepressants & 1 & 1 & & \\
\hline CPZ equivalent daily dose of combined use of APS & $242.35 \pm 198.26$ & $342.50 \pm 232.45$ & 1.44 & $>0.05$ \\
\hline
\end{tabular}

$A P S$ antipsychotics, $C P Z$ chlorpromazine

visit in each group or between groups before and after treatment.

All missing data at each follow-up visit were randomized missing data by randomized analysis, and the missing data at each follow-up visit were replaced using the last observation carried forward method (LOCF) when ITT analyses was performed.

Compared with the baseline in each group, the body weight, BMI and most waist-hip ratio at each followup visit markedly decreased (all $P$ value $<0.001$ ), only waist-hip ratio at week 4 of follow-up visit significantly decreased in the topiramate group $(t=2.63, P<0.05)$, while no differences of weight loss, BMI, and waist-hip reduction ratio were found at each follow-up visit compared with baseline in the metformin group (see Fig. 2).

Compared with the metformin group, only weight and BMI at week 4 of follow-up visit in the topiramate group significantly declined $(t=4.38, P<0.05 ; t=9.28, P<0.01)$, but there was no difference in waist-hip ratio at 4 weeks of follow-up visit between the two groups. The reduction

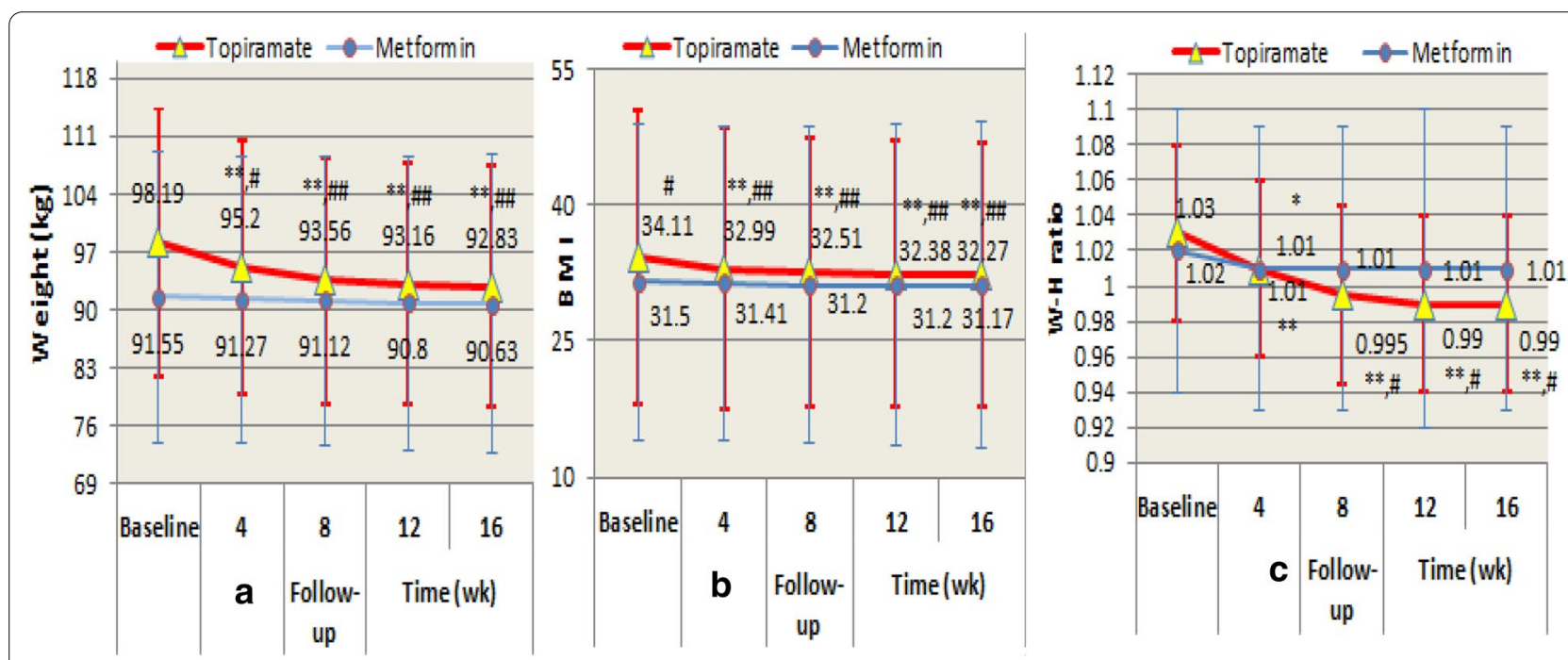

Fig. 2 ITT analyses showed change in weight (a), BMI (b), and W-H ratio (c) during treatment: compared with baseline: ${ }^{*} P<0.05$, ${ }^{* *} P<0.001 ;$ with metformin: ${ }^{\#} P<0.05$, ${ }^{\# \#} P<0.01$ 
of weight, BMI, and waist-hip ratio at 8,12 , and 16 weeks of follow-up visit in the topiramate group were all remarkably more than that in the metformin group $(P<0.05$, or $P<0.001)$ (see Fig. 2$)$.

\section{Completer analyses}

Effects of combined treatment with topiramate or metformin on weight, BMI and WHR of patients who completed the entire trial at each follow-up in each group or between the two groups before and after concomitant treatment.

Figure 1 shows the status of completed this trail at each follow-up visit. Only 10 cases of patients in the topiramate group and 15 cases of patients in the metformin group at week 16 of follow-up visit were included in the completer analyses. The loss rate of follow-up was similar at weeks 4-16 of follow-up visit between the two groups (all $P>0.05$ ) (see Table 1).

Compared with the baseline in each group, statistically significant reductions of weight, BMI, and $\mathrm{W}-\mathrm{H}$ ratio from weeks 4 to 16 of follow-up were found in the topiramate group (all $P$ value $<0.001$ ). However, only statistically remarkable reduction of $\mathrm{W}-\mathrm{H}$ ratio at week 4 of follow-up visit was found in the metformin group $(P<0.05)$, there were no differences in weight loss and BMI reduction at week 4 of follow-up visit, and the differences in three main measurements at other follow-up visit were also not found in the metformin group (see Fig. $3 \mathrm{a}-\mathrm{c}$ ).

Compared with the metformin group, there was significant difference in reduction of BMI from weeks 4 to 16 of follow-up visit in the topiramate group $(P<0.05-0.01)$, and there were also marked weight loss and $\mathrm{W}-\mathrm{H}$ ratio at other follow-up visit were not found between the two groups (see Fig. 3a-c).

\section{Adverse events}

There were 2 cases of outpatients with both dizziness and poor appetite, one case of patient with diarrhea, abnormal liver function and exacerbation of illness in the topiramate group during the trial. Only 2 cases of outpatients with abnormal liver function or 2 cases with exacerbation of illness were reported in the metformin group after 16-week clinical trial, respectively. There were no significant differences in above adverse events between the two groups, no other intolerable adverse events, such as severe organic impairment, were found between the two groups during the trial $(P>0.05)$. One patient presented with worsening psychiatric symptoms in the topiramate group and two patients in the metformin group were found after the end of this study, no significant difference in worsening psychiatric symptoms was found between the two groups.

\section{Discussion}

Although some previous research suggested that metformin may have robust role of weight loss, this study further indicated that topiramate was significantly superior, at least similar, to metformin in managing established weight gain or obesity caused by some second-generation antipsychotics by ITT and completer analyses in the case of keeping the patient's illness stable and maintaining the original antipsychotic treatment. The benefits from weeks 4 to 16 of follow-up visit after treatment of concomitant topiramate were emerged whether in terms of weight loss or BMI and waist-hip ratio reduction both by ITT analysis and completion analysis. It also indi-
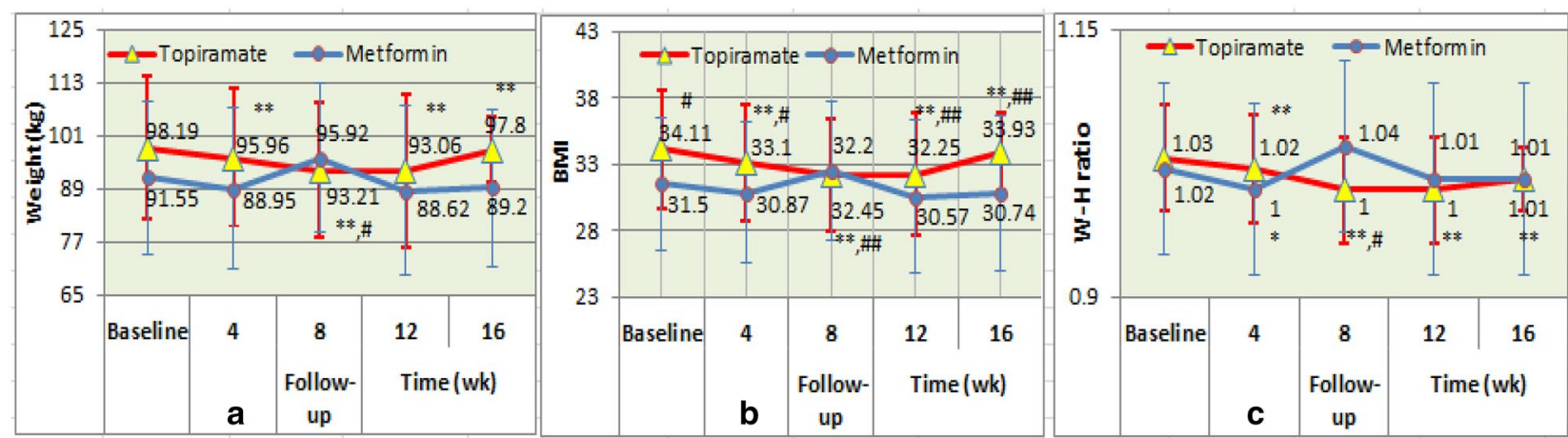

Fig. 3 Completer analyses showed change in weight (a), BMI (b), and W-H ratio (c) during treatment: compared with baseline: ${ }^{*} P<0.05$, ${ }^{* *} P<0.001$; with metformin: ${ }^{P} P<0.05$

reduction at week 8 of follow-up visit in the topiramate group, but the differences in above three measurements cated that topiramate has a faster and better therapeutic effect on obesity caused by SGAs. Whereas, the effects 
of concomitant metformin on obesity associated with atypical antipsychotics were not significant, and only waist-hip ratio reduction at week 4 of follow-up visit remarkably decreased compared with the baseline by ITT analyses and completer analyses. The results associated with topiramate were consistent with most studies' reports and meta-analyses reviews [6, 19, 29-31]. Whereas, the results related to metformin in this study were not completely consistent with some previous studies' reports, especially in terms of weight loss [13, 14, 32]. This may be associated with lower dosage of metformin being used in this study. Topiramate has been approved as a weight loss drug with concomitant use of phentermine by the US Drug Administration (FDA) [33], and most previous studies' results also revealed that topiramate has a significant antipsychotic effect and weight loss, although not all studies' results related to the effects of topiramate on psychosis are consistent [34, 35].

The comparison between concomitant use of topiramate and metformin revealed that topiramate has a robust therapeutic effect on obesity induced by some SGAs during the vast majority of follow-up visit in this trial. This was consistent with most previous meta-analyses results [6, 19]. Nevertheless, it was not consistent with Ellinger's review [10], which indicated the use of metformin resulted in greater weight loss than topiramate. This perhaps was associated with Ellinger's review without a meta-analyses and statistical test.

It should be noted that, during the trial, the weight at week 8 elevated transitorily in the metformin group, and it did so at week 16 in the topiramate group. All this suggested that outpatients in the real world often cannot follow the experimental requirements, especially in outpatients with mental disorders. They even frantically failed to control their diet and refused to take part in all activities, particularly during the onset of certain mental illnesses.

The mechanism of weight loss for topiramate was mainly associated with its decreasing appetite and increasing satiety, but did not change energy expenditure, probably by means of inhibition of carbonic anhydrase [6]. In addition, topiramate itself also played a role in schizophrenia, which was considered to be mediated by antagonism of glutamate-caused excitotoxicity at the kainic acid (KA)/alpha-amino-3-hydroxy-5-Methylisoxazole-4-propionic acid (AMPA) glutamate receptors [36]. Altered levels of free glutamate, in which topiramate serves as an antagonist, have been found in schizophrenic patients compared with healthy controls [22].

There were no significant differences regarding the loss rate of follow-up at each follow-up visit, the incidence of adverse events, and the number of recurrence of the original mental disorders between the two groups during the trial, which suggested that the tolerance and safety of topiramate and metformin were similar when they were utilized to treat weight gain or obesity induced by SGAs. However, the results of this study were not exactly consistent with some previous reviews or study results [6, 10]. It was perhaps related to the absence of statistical tests about adverse events in these reports.

The use of topiramate, of course, also has some rare adverse events, such as dizziness, diarrhea, and inappetence, which should not be ignored, although there were no difference between the two groups. However, the diarrhea and inappetence would be significantly alleviated after reducing the dose of topiramate. To be sure, the recurrence or worsening of illness in some outpatients was mostly due to non-compliance for the antipsychotic treatment during the trial, instead of associating with the concomitant use of topiramate or metformin, although it was not consistent with Choi et al's report [37].

As to the effects of topiramate on maintaining stability in schizophrenia or affective disorders, in this study, only three cases of psychiatric symptoms worsen were found in the topiramate and metformin group at the end of this study, and no significant difference was found between the two groups. Therefore, there were no enough evidence to prove that topiramate might stabilize the illness of schizophrenia and affective disorders according to this results.

There are some limitations to this study. First, the dosage of metformin in this study was relatively lower than that in other previous studies. This may be one of the reasons why metformin reversed antipsychotics-induced obesity was inferior to topiramate. Secondly, the number of cases in the study was relatively small. And the number of completer was also gradually decreased with the increase of follow-up time, which needs more concerns in future research, although there was no remarkable difference in the loss rate of follow-up between the two groups.

In summary, in the treatment of weight gain or obesity induced by some SGAs, topiramate holds great promise for reducing weight gain, BMI, and waist-hip ratio compared to metformin, although metformin may be a more appropriate agent in people with obesity or diabetes. Of course, the ideal approach to weight loss should be also highly individualized, identifying appropriate medications, and behavioral intervention.

\section{Conclusion}

The topiramate, as an adjunctive therapy, is similar to metformin in reducing obesity as previously reported. It also significantly decreases antipsychotic-induced obesity and waist-hip ratio in patients with schizophrenia, 
affective disorder, etc., and has a better acceptability and fewer adverse effects.

\section{Abbreviations}

BMI: Body mass index; W-H ratio: Waist-hip ratio; LOCF: Last observation carried forward method; SGAs: Second-generation antipsychotics; H2: Histamine 2; ITT: Intention-to-treat.

\section{Acknowledgements}

We would like to thank Min Chen for providing English language editing service.

\section{Authors' contributions}

CW and JX designed the study. WS, CH, and JZ collected the clinical data and performed the psychiatric assessment. CW analyzed the data and wrote the paper. All authors read and approved the final manuscript.

\section{Funding}

The authors received no financial support for the research, authorship, and/or publication of this article.

\section{Consent for publication}

The authors declared no potential conflicts of interest with respect to the research, authorship, and/or publication of this article.

\section{Competing interests}

The authors declare that they have no competing interests.

Received: 21 July 2020 Accepted: 25 November 2020

Published online: 10 December 2020

\section{References}

1. Maayan L, Correll CU. Management of antipsychotic-related weight gain. Expert Rev Neurother. 2010;10(7):1175-200.

2. Anagnostou E, Aman MG, Handen BL, Sanders KB, Shui A, Hollway JA, et al. Metformin for treatment of overweight induced by atypical antipsychotic medication in young people with autism spectrum disorder: a randomized clinical trial. JAMA Psychiatry. 2016;73(9):928-37.

3. Ng M, Fleming T, Robinson M, Thomson B, Graetz N, Margono C, et al. Global, regional, and national prevalence of overweight and obesity in children and adults during 1980-2013: a systematic analysis for the Global Burden of Disease Study 2013. Lancet. 2014;384(9945):766-81.

4. Erickson ZD, Kwan CL, Gelberg HA, Arnold IY, Chamberlin V, Rosen JA et al. A Randomized, controlled multisite study of behavioral interventions for veterans with mental illness and antipsychotic medicationassociated obesity. J Gen Intern Med. 2017;32(Suppl 1):32-9.

5. Brown C, Goetz J, Hamera E, Gajewski B. Treatment response to the RENEW weight loss intervention in schizophrenia: impact of intervention setting. Schizophr Res. 2014;159(2-3):421-5.

6. Fiedorowicz JG, Miller DD, Bishop JR, Calarge CA, Ellingrod VL, Haynes WG. Systematic review and meta-analysis of pharmacological interventions for weight gain from antipsychotics and mood stabilizers. Curr Psychiatry Rev. 2012;8(1):25-36.

7. Reekie J, Hosking SP, Prakash C, Kao KT, Juonala M, Sabin MA. The effect of antidepressants and antipsychotics on weight gain in children and adolescents. Obes Rev. 2015;16(7):566-80.

8. Larsen JR, Vedtofte L, Jakobsen MSL, Jespersen HR, Jakobsen MI, Svensson CK, et al. Effect of liraglutide treatment on prediabetes and overweight or obesity in clozapine-or olanzapine-treated patients with schizophrenia spectrum disorder: a randomized clinical trail. JAMA Psychiatry. 2017;74(7):719-28.

9. Zhuo C, Xu Y, Liu S, Li J, Zheng Q, Gao X, et al. Treatments in controlling antipsychotic-induced weight gain: a systematic review and network meta-analysis. Front Pharmacol. 2018a;28(9):1393.

10. Ellinger LK, Ipema HJ, Stachnik JM. Efficacy of metformin and topiramate in prevention and treatment of second-generation antipsychoticinduced weight gain. Ann Pharmacother. 2010;44(4):668-79.
11. Bouza C, López-Cuadrado T, Gutierrez-Torres LF, Amate J. Efficacy and safety of metformin for treatment of overweight and obesity in adolescents: an updated systematic review and meta-analysis. Obes Facts. 2012;5(5):753-65

12. Yanovski JA, Krakoff J, Salaita CG, McDuffie JR, Kozlosky M, Sebring NG, et al. Effects of metformin on body weight and body composition in obese insulin-resistant children: a randomized clinical trial. Diabetes. 2011;60(2):477-85.

13. Zheng W, Li XB, Tang YL, Xiang YQ, Wang CY, de Leon J. Metformin for weight gain and metabolic abnormalities associated with antipsychotic treatment: meta-analysis of randomized placebo-controlled trials. J Clin Psychopharmacol. 2015;35(5):499-509.

14. Jarskog LF, Hamer RM, Catellier DJ, Stewart DD, Lavange L, Ray N, METS Investigators, et al. Metformin for weight loss and metabolic control in overweight outpatients with schizophrenia and schizoaffective disorder. Am J Psychiatry. 2013;170(9):1032-40.

15. Klein DJ, Cottingham EM, Sorter M, Barton BA, Morrison JA. A randomized, double-blind, placebo-controlled trial of metformin treatment of weight gain associated with initiation of atypical antipsychotic therapy in children and adolescents. Am J Psychiatry. 2006;163:2072-9.

16. Ochoa JG. Topiramate improves psychiatric symptoms in a patient with Lewy body dementia. Cogn Behav Neurol. 2014;27(4):222-3.

17. Lung FW, Liu CL, Wang CS, Tzeng DS. Adjunctive topiramate treatment for a refractory familial adolescent mania. World J Biol Psychiatry. 2009;10(1):74-7.

18. Veerman SRT, Schulte PFJ, de Haan L. Treatment for negative symptoms in schizophrenia: a comprehensive review. Drugs. 2017. https://doi. org/10.1007/s40265-017-0789-y.

19. Khazaal Y, Chatton A, Rusca M, Preisig M, Zullino D. Long-term topiramate treatment of psychotropic drug-induced weight gain: a retrospective chart review. Gen Hosp Psychiatry. 2007;29(5):446-9.

20. Mahmood S, Booker I, Huang J, Coleman Cl. Effect of topiramate on weight gain in patients receiving atypical antipsychotic agents. J Clin Psychopharmacol. 2013;33(1):90-4.

21. Powell A. Obesity pharmacotherapy. FP Essent. 2020;492:25-9.

22. Afshar H, Roohafza H, Mousavi G, Golchin S, Toghianifar N, Sadeghi M, et al. Topiramate add-on treatment in schizophrenia: a randomised, double-blind, placebo-controlled clinical trial. J Psychopharmacol. 2009;23(2):157-62.

23. Milano W, De Biasio V, Di Munzio W, Foggia G, Capasso A. Obesity: the new global epidemic pharmacological treatment, opportunities and limits for personalized therapy. Endocr Metab Immune Disord Drug Targets. 2020;20(8):1232-43

24. McElroy SL, Frye MA, Altshuler LL, Suppes T, Hellemann G, Black D, Mintz J, et al. A 24-week, randomized, controlled trial of adjunctive sibutramine versus topiramate in the treatment of weight gain in overweight or obese patients with bipolar disorders. Bipolar Disord. 2007;9(4):426-34.

25. Wang CJ, Zhang ZJ, Sun J, Zhang XB, Mou XD, Zhang XR, et al. Serum free fatty acids and glucose metabolism, insulin resistance in schizophrenia with chronic antipsychotics. Biol Psychiatry. 2006;60:1309-13.

26. Little RJ, D'Agostino R, Cohen ML, Dickersin K, Emerson SS, Farrar JT, et al. The prevention and treatment of missing data in clinical trials. N Engl J Med. 2012:67:1355-60.

27. Gardner DM, Murphy AL, O'Donnell H, Centorrino F, Baldessarini RJ. International consensus study of antipsychotic dosing. Am J Psychiatry. 2010;167:686-93.

28. Lee J, Remington G. Adequate dosing for second-generation antipsychotics in establishing treatment resistance in schizophrenia. Am J Psychiatry. 2014;171(1):118-9.

29. Evers SS, van Vliet A, van Vugt B, Scheurink AJ, van Dijk G. A low TSH profile predicts olanzapine-induced weight gain and relief by adjunctive topiramate in healthy male volunteers. Psychoneuroendocrinology. 2016;66:101-10.

30. Levy E, Agbokou C, Ferreri F, Chouinard G, Margolese HC. Topiramateinduced weight loss in schizophrenia: a retrospective case series study. Can J Clin Pharmacol. 2007;14(2):e234-9.

31. Zhuo CJ, Xu Y, Liu S, Li J, Zheng QS, Gao XY, et al. Topiramate and metformin are effective add-on treatments in controlling antipsychoticinduced weight gain: a systematic review and network meta-analysis. Front Pharmacol. 2018b;28(9):1393. 
32. Wu RR, Jin H, Gao K, Twamley EW, Ou JJ, Shao P, et al. Metformin for treatment of antipsychotic-induced amenorrhea and weight gain in women with first-episode schizophrenia: a double-blind, randomized, placebocontrolled study. Am J Psychiatry. 2012;169(8):813-21.

33. Khera R, Murad MH, Chandar AK, Dulai PS, Wang Z, Prokop LJ, et al. Association of pharmacological treatments for obesity with weight loss and adverse events: a systematic review and meta-analysis. JAMA 2016;315(22):2424-34.

34. Behdani F, Hebrani P, Rezaei Ardani A, Rafee E. Effect of topiramate augmentation in chronic schizophrenia: a placebo-controlled trial. Arch Iran Med. 2011;14(4):270-5.

35. Muscatello MR, Bruno A, Pandolfo G, Micò U, Bellinghieri PM, Scimeca G, et al. Topiramate augmentation of clozapine in schizophrenia: a doubleblind, placebo-controlled study. J Psychopharmacol. 2011;25(5):667-74.
36. Drapalski AL, Rosse RB, Peebles RR, Schwartz BL, Marvel CL, Deutsch SI. Topiramate improves deficit symptoms in a patient with schizophrenia when added to a stable regimen of antipsychotic medication. Clin Neuropharmacol. 2001;24(5):290-4.

37. Choi YJ. Efficacy of adjunctive treatments added to olanzapine or clozapine for weight control in patients with schizophrenia: a systematic review and meta-analysis. Sci World J. 2015. https://doi.org/10.1155/2015/97073

0 (Epub 2015 Jan 13).

\section{Publisher's Note}

Springer Nature remains neutral with regard to jurisdictional claims in published maps and institutional affiliations.
Ready to submit your research? Choose BMC and benefit from:

- fast, convenient online submission

- thorough peer review by experienced researchers in your field

- rapid publication on acceptance

- support for research data, including large and complex data types

- gold Open Access which fosters wider collaboration and increased citations

- maximum visibility for your research: over $100 \mathrm{M}$ website views per year

At BMC, research is always in progress.

Learn more biomedcentral.com/submissions 